\title{
PELAKSANAAN PELAYANAN KARTU TANDA PENDUDUK ELEKTRONIK ( e-KTP) DALAM MENDUKUNG SISTEM ADMINISTRASI KEPENDUDUKAN DI KOTA JAYAPURA
}

\section{ELECTRONIC IDENTITY CARD (E-KTP) SERVICE IN SUPPORT ADMINISTRATION SYSTEM IN THE JAYAPURA CITY}

\author{
Agus Hartopo \\ Bidang Penelitian dan Pengembangan \\ Badan Perencanaan Pembangunan Daerah Provinsi Papua \\ Jl. Soasiu Dok II Jayapura Papua \\ No. Telp./Faxs : + 620967535334 \\ e-mail : hartopoagus@yahoo.com \\ Dikirim: 3 Februari 2013; direvisi: 8 Maret 2013; disetujui: 18 Maret 2013
}

\begin{abstract}
Abstrak
Penelitian ini bertujuan untuk: mengetahui capaian perekaman e-KTP di Kota Jayapura; menganalisa hubungan jumlah penduduk wajib e-KTP dengan penyelesaian perekaman; menginventarisir hambatan dalam perekaman e-KTP; menginventarisir upaya yang telah dilakukan oleh Pemerintah Kota Jayapura mengatasi kendala perekaman e-KTP; mengetahui rasio alat perekaman dengan jumlah penduduk wajib eKTP. Metodologi yang digunakan untuk menganalisa hubungan variabel menggunakan korelasi dengan bantuan sofware SPSS 19, serta prosentase. Hasil penelitian menunjukan: pelaksanaan kebijakan e-KTP di Kota Jayapura telah dilaksanakan dan mencapai kemajuan yang signifikan. Perkembangan perekaman eKTP pada akhir tahun 2012, menunjukan hingga 89 \%. Dalam jangka waktu 5 bulan (dari bulan Agustus Desember 2012) mengalami perkembangan sebesar $5 \%$.Terdapat hubungan yang siginfikan antara jumlah penduduk dengan wajib e-KTP dalam arti semakin besar jumlah penduduk di Kota Jayapura akan semakin besar pula penduduk wajib e-KTP. Sebaliknya terdapat hubungan antara jumlah wajib e-KTP dengan penyelesian perekaman e-KTP. Dalam pelaksanaan perekaman e-KTP ditemukan sejumlah hambatan. Hambatan yang muncul telah diatasi dengan berbagai upaya yang telah dilaksanakan oleh Pemerintah Kota Jayapura.
\end{abstract}

Kata kunci: e-KTP, kota jayapura, perekaman, hambatan, pemerintah.

\begin{abstract}
This study aim to know target taping e-KTP at Municipality Jayapura, analyse corelation total population compulsory e-KTP with complition taping, inventory effort by Goverment Municipality Jayapura overcome constraints taping e_KTP, know ratio too taping with total population compulsory e-KTP.The study shows that implemention policy e-KTP at municipality Jayapura has been implemented and achieve progress significant. Development tapiong e-KTP at year end 2012, have shown until $89 \%$. In the period 5 mounth (from August - December 2012) development $5 \%$. There is a relationship significant betwenn total population and compulsary e-KTP, in the sense greather total population at Municipality Jayapura will greather total population compulsory e-KTP. Otherwise relation between total compulsary e-KTP with completion taping e-KTP. In implementaion taping e-KTP finds obstacle appear has been overcome by kinds effort has been implemented by local Goverment Municipality Jayapura.
\end{abstract}

Keywords: e-KTP, municipality jayapura, taping, obstacle, recording equipment.

\section{PENDAHULUAN}

Pelaksanaan penerapan Kartu Tanda Penduduk Elektronik (e-KTP) didasarkan pada Undang-Undang nomor 23 Tahun 2006 tentang Administrasi Kependudukan. Peraturan lainnya yang mengatur penerapan e-KTP yaitu : Peraturan Presiden nomor 26 tahun 2009 tentang penerapan KTP berbasis NIK secara Nasional sebagaimana telah diubah dengan Peraturan Presiden Nomer 35 tahun 2010, Keputusan Menteri Dalam Negeri nomor 471.130.5-335 tentang pembentukan tim teknis penerbitan NIK \& Penerapan KTP Berbasis NIK secara Nasional, Peraturan Menteri dalam Negeri No 6 tahun 2011 tentang standar \& spesifikasi perangakt lunak \& blanko KTP berbasis NIK secara Nasional, Peraturan Menteri Dalam negeri No. 9 tahun 2011 tentang pedoman penerbitan KTP berbasis NIK secara nasional, Surat edaran Menteri Dalam Negeri nomor. 471.13/2715/MD tanggal 16 Juni 2010 tentang Pemutahiran Data Kependudukan Penerbitan NIK dan persiapan e-KTP dan surat edaran menteri dalam negeri nomor. 
471.13/4141/SJ tanggal 13 Oktober 2010 tentang Penerbitan NIK dan persiapan e-KTP tahun 2011.

Pemerintah Kota Jayapura melaksanakan pemberlakuan kartu tanda penduduk elektronik (eKTP) sejak tahun 2011. Pemberlakukan ini diawali dengan perekaman bagi setiap penduduk wajib eKTP. Pada tahun yang sama, kabupaten yang mulai melaksanakan perekaman secara bersamaan yaitu : Kabupaten Sarmi, Kabupaten Merauke dan Kabupaten Jayapura.

Penduduk Kota Jayapura berjumlah 256.705 pada tahun 2012. Dari total jumlah penduduk, penduduk wajib e-KTP Kota Jayapura berjumlah 157.741, (61,4 persen). Sedangkan dari total penduduk wajib e-KTP Provinsi Papua 2.999.382. maka penduduk wajib e-KTP sebesar 5,3 persen berdomisili di Kota Jayapura. Penduduk Kota Jayapura tersebar ke dalam lima distrik meliputi : Jayapura Utara, Jayapura Selatan, Abepura, Heram dan Muara Tami.

Pelayanan perekaman e-KTP dilaksanakan di setiap distrik. Perangkat perekaman dan operator eKTP ditempatkan di setiap Distrik. Pelayanan dibuka dari pagi jam 08.00 hingga selesai, bahkan sampai malam hari jika banyak yang datang melakukan perekaman. Perekaman tidak dikenakan biaya (gratis). Himbauan selalu disampaikan dari Pemerintah Kota Jayapura, agar penduduk segera melakukan perekaman dalam batas waktu yang telah ditentukan. Penduduk Kota Jayapura pada dasarnya sadar arti penting dari e-KTP. Namun karena keterbatasan alat perekam, maka mengantri menunggu giliran. Banyaknya wajib e-KTP yang ingin segera melakukan perekaman berakibat antrian di kantor Distrik. Hal ini mengakibatkan ada penduduk yang mengurungkan niat melakukan perekaman.

Pemerintah Kota Jayapura mempunyai tugas dan kewajiban dalam memberikan pelayanan e-KTP. Kesiapan petugas perekam turut menentukan tingkat layanan dan target penyelesaian e-KTP. Pelayanan perekaman dilakukan pula pada kelurahan pada harihari tertentu. Pelayanan di keluruhan mengikuti jadwal yang telah ditentukan, mengingat alat perekaman terbatas. Pada dasarnya perekaman dapat dilaksanakan dimana saja, karena alat perekam terhubung dengan jaringan internet. Jaringan internet ini terhubung dengan pusat (KEMENDAGRI) untuk selanjutnya dilakukan pencetakan e-KTP di Jakarta dan dikirim kembali ke Kota Jayapura.

Penggunaan jaringan internet di Kota Jayapura terkadang mengalami kendala tidak ada signal. Hal serupa dialami Kabupaten Tasikmalaya, listrik sering mati berakibat jaringan internet kurang kuat (www.pikiranrakyat.com). Listrik di Kota Jayapura dilayani PLN. Pembangkit listrik yang digunakan pembangkit listrik tenaga disel (PLTD).

Program e-KTP yang didalamnya tercantum Nomor Induk Kependudukan (NIK) dalam jangka panjang dapat digunakan dan dijadikan sebagai dasar dalam penerbitan Paspor, Surat Izin Mengemudi (SIM), Nomer Pokok Wajib Pajak (NPWP), Polis Asuransi, Sertifikat Hak Atas Tanah serta penerbitan identitas laiinya (UU 23 Tahun 2006 Psl. 13) . Selain itu dalam penentuan Daftar pemilih tetap (DPT) dapat memanfaatkan data base e-KTP. Dengan demikian akan mendukung suksesnya Pemilu/Pemilukada. Tersedianya data pemilih tetap (DPT) maka akan meningkatkan pelayanan publik, karena hak pilih setiap penduduk sudah tersedia.

Meskipun Kota Jayapura merupakan daerah perkotaan masih ditemukan penduduk yang belum melakukan perekaman e-KTP. Salah satu alasan yang muncul ditemukan penduduk tidak bersedia diambil data iris mata. Alasan ini menjadi salah satu hambatan dalam pelaksanaan perekaman data eKTP. Pemerintah Kota melalui Dinas Kependudukan dan Catatan Sipil melakukan pendekatan-pendekatan agar perekaman dapat dilaksanakan kepada seluruh penduduk yang wajib e-KTP. Slogan dalam mencapai wajib e-KTP “ Kota Jayapura Wajib eKTP”

Kota Jayapura sangat mudah diakses dari laut maupun udara dari luar daerah. Akibatnya jumlah penduduk Kota Jayapura bertambah akibat migrasi masuk. Sarana anggkutan yang digunakan dari laut berupa kapal PELNI ( kapal putih). Dalam Satu minggu terdapat dua kali kapal masuk ke Jayapura. Meskipun secara dejure penduduk yang datang merupakan warga kota Jayapura tetapi hanya berstatus domisili. Kartu Tanda Penduduk yang dimiliki masih merupakan penduduk daerah asal (Jawa, Sulawesi dan laiinya).

Dari latar belakang yang dikemukan maka dirumuskan masalah yang hendak diteliti yaitu :a) Bagaimanakah capaian perekaman e-KTP di Kota Jayapura; b) Bagaimana hubungan antara jumlah penduduk wajib e-KTP dengan penyelesaian perekaman; c) Hambatan apa saja yang menjadi kendala dalam perekaman e-KTP; d) Upaya apa saja yang telah dilakukan oleh Pemerintah Kota Jayapura mengatasi kendala perekaman e-KTP; d) Bagaimanakah rasio alat perekaman dengan jumlah penduduk wajib e-KTP.

Penelitian ini bertujuan untuk : a) Mengetahui capaian perekaman e-KTP di Kota Jayapura; b) Menganalisa hubungan antara jumlah penduduk wajib e-KTP dengan penyelesaian perekaman; c) Menginventarisir hambatan yang menjadi kendala dalam perekaman e-KTP; d) Menginventarisir upaya yang telah dilakukan oleh Pemerintah Kota Jayapura mengatasi kendala perekaman e-KTP; d) Mengetahui rasio alat perekaman dengan jumlah penduduk wajib e-KTP.

Kegunaan penelitian ini akan memberikan kontribusi praktis Pemerintah Kota Jayapura dalam pelaksanaan e-KTP. Setelah diketahui capaian perekaman selama tahun 2012 akan dapat diambil langkah-langkah dalam penyelesaian perekaman eKTP. 


\section{METODOLOGI PENELITIAN}

Penelitian ini bersifat deskriptif, yaitu menerangkan keadaan sebenarnya. Sumber data penelitian terdiri dari data Primer dan sekunder. Data primer diperoleh langsung dari lapangan. Pengumpulan data primer dilakukan dengan terdapat di sepanjang jalan Abepura-Sentani. Mall Abepura menjadi pusat perdagangan modern. Wilayah dengan berbagai fasilitas yang tersedia menarik penduduk untuk tinggal, sehingga Distrik Abepura jumlah penduduk paling banyak. Mata pencaharian penduduk non pertanian.

Distrik Muaratami berada pada daerah perbatasan. Terdiri dari perkampungan asli dan eks

Tabel 1: Distribusi Penduduk Kota Jayapura

\begin{tabular}{llllll}
\hline No. & Distrik & Jumlah Penduduk & Wajib KTP & Persentase & Keterangan \\
\hline 1 & Jayapura Utara & 65.039 & 39.664 & 25,4 & \\
2 & Jayapura Selatan & 66.937 & 40.565 & 26,1 & \\
3 & Abepura & 73.157 & 45.626 & 28,5 & \\
4 & Muara Tami & 11.137 & 6.729 & 4,4 & \\
5 & Heram & 40.435 & 25.157 & 15,6 & \\
\hline & Jumlah & $\mathbf{2 5 6 . 7 0 5}$ & $\mathbf{1 5 7 . 7 4 1}$ & $\mathbf{1 0 0}$ & \\
\hline
\end{tabular}

Sumber : Dinas DUKCAPIL Kota Jayapura Desember 2012 (Data Diolah)

menggunakan metode wawancara. Wawancara dilakukan dengan petugas operator dan Kabid informasi data Dinas Kependudukan dan Catatan Sipil Kota Jayapura Provinsi Papua. Sumber data sekunder berasal dari data-data realisasi perekaman Dinas Kependudukan dan Catatan Sipil. Metode analisa menggunakan Mixed Methods yaitu gabungan antara kuantitatif dan kualitatif (Jonathan Sarwono : 2011). Pengolahan data menggunakan SPSS versi 19 untuk melihat korelasi. Koefisien korelasi menurut Sugiyono (2007) sebagai berikut :
$0,00-0,199$
= sangat rendah
$0,20-0,399$
$=$ rendah
$0,40-0,599$
= sedang
$0,60-0,799$
$=$ kuat
= sangat kuat
$0,80-1,000$

Alat analisis digunakan untuk melihat hubungan variabel jumlah penduduk dengan jumlah penduduk wajib e-KTP.

\section{HASIL DAN PEMBAHASAN}

\section{Gambaran Umum}

Penduduk Kota Jayapura terdiri bermacam suku bangsa. Hampir semua suku tinggal di Kota Jayapura. Dari tabel 1 menunjukan jumlah penduduk terbanyak berada di Distrik Abepura. Sedangkan jumlah penduduk paling sedikit terdapat di Distrik Muara Tami.

Distrik Abepura merupakan pusat kegiatan ekonomi dan pendidikan. Fasilitas pendidikan dari tingkat TK sampai perguruan tinggi terletak di Distrik Abepura. Perguruan tinggi Negeri tertua di Papua yaitu Universitas Cenderawasih terletak di Distrik ini. Perguruan tinggi swasta terdiri Universitas OttoGeisler, Universitas Sains Teknologi Jayapura, Universitas Umel Mandiri, Sekolah Tinggi Komunikasi.Kegiatan perekonomian pada distrik ini ditunjang pasar tradisional terbesar di Kota Jayapura yaitu pasar Youtefa. Pusat perbelanjaan modern transmigrasi. Perkampungan asli meliputi: Skowsae, Skowyambe, Skow Mabo dan Kampung Moso. Daerah eks transmigrasi meliputi Koya Barat, Koya Timur, Koya Tengah. Mata pencaharian penduduk sebagian besar pertanian dan nelayan. Muaratami menjadi hinterland Kota Jayapura. Kebutuhan sayur mayur dan hasil pertanian dipasok dari distrik ini. Daerah pertanian terutama di Koya Barat, Koya Timur, Koya Tengah.

Perbandingan penduduk dan wajib e-KTP dapat dilihat pada gambar 1 .

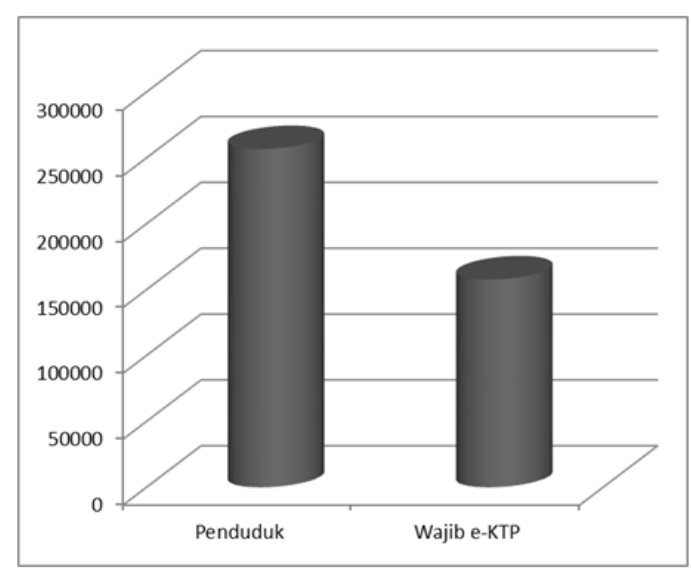

Gambar 1: Perbandingan Jumlah Penduduk dan Wajib e-KTP.

\section{Capaian Perekaman e-KTP}

Perekaman e-KTP dilaksanakan dari Tahun 2011 seiring dengan pencanangan secara Nasional. Kantor Distrik (Kecamatan) merupakan tempat perekaman bagi penduduk yang telah menerima undangan perekaman. Undangan perekaman mencantumkan tempat, dan tanggal perekaman. Masing-masing penduduk menerima satu undangan. Undangan yang diberikan sesuai dengan nama yang tercantum dalam Kartu Keluarga. Hasil perekaman dapat dilihat pada tabel 1. Data yang digunakan 
dalam penelitian ini terdiri data Bulan Agustus 2012 ( pameran pembangunan Kota Jayapura) dan data akhir tahun 2012 ( tabel 2).

Tabel 2 Perekaman e-KTP Kota Jayapura Penduduk Wajib E-KTP

\begin{tabular}{|c|c|c|c|c|}
\hline No. & Distrik & $\begin{array}{l}\text { Wajib } \\
\text { KTP }\end{array}$ & $\begin{array}{l}\text { Sudah } \\
\text { Terekam }\end{array}$ & Persentase \\
\hline 1 & $\begin{array}{l}\text { Jayapura } \\
\text { Utara }\end{array}$ & 39.664 & 35.385 & 89 \\
\hline 2 & $\begin{array}{l}\text { Jayapura } \\
\text { Selatan }\end{array}$ & 40.565 & 34.393 & 85 \\
\hline 3 & Abepura & 45.626 & 37.204 & 82 \\
\hline 4 & $\begin{array}{l}\text { Muara } \\
\text { Tami }\end{array}$ & 6.729 & 6.401 & 95 \\
\hline \multirow[t]{2}{*}{5} & Heram & 25.157 & 19.725 & 78 \\
\hline & & 157.741 & 133.108 & 84 \\
\hline
\end{tabular}

Sumber : Dinas Kependudukan dan Catatan Sipil Kota Jayapura, Agustus 2012 maka akan lebih cepat perekamannya. Maka dapat dilihat bahwa wajib e-KTP Distrik lebih sedikit maka penyelesaian perekaman lebih tinggi pencapaiannya.

Di Distrik Heram terdapat pusat pendidikan perguruan Tinggi UNCEN lokasi baru. Pada distrik ini pencapaian prosentase paling rendah. Hal ini dipahami karena terjadi mobilitas tinggi. Mobilitas ini ada kaitannya dengan penduduk wajib e-KTP yang sedang melaksanakan studi lanjut maupun sering melaksanakan tugas keluar daerah Papua. Mobilitas penduduk yang tinggi ini menyebabkan penduduk wajib e-KTP yang dipanggil perekaman berdasarkan undangan tidak dapat mengikuti perekaman. Undangan perekaman menjadi dasar penduduk mendapatkan pelayanan KTP. Pelayanan KTP termasuk salah satu pelayanan untuk tertib administrasi kependudukan. Penduduk di Distrik Heram selain tinggal di pemukiman masih

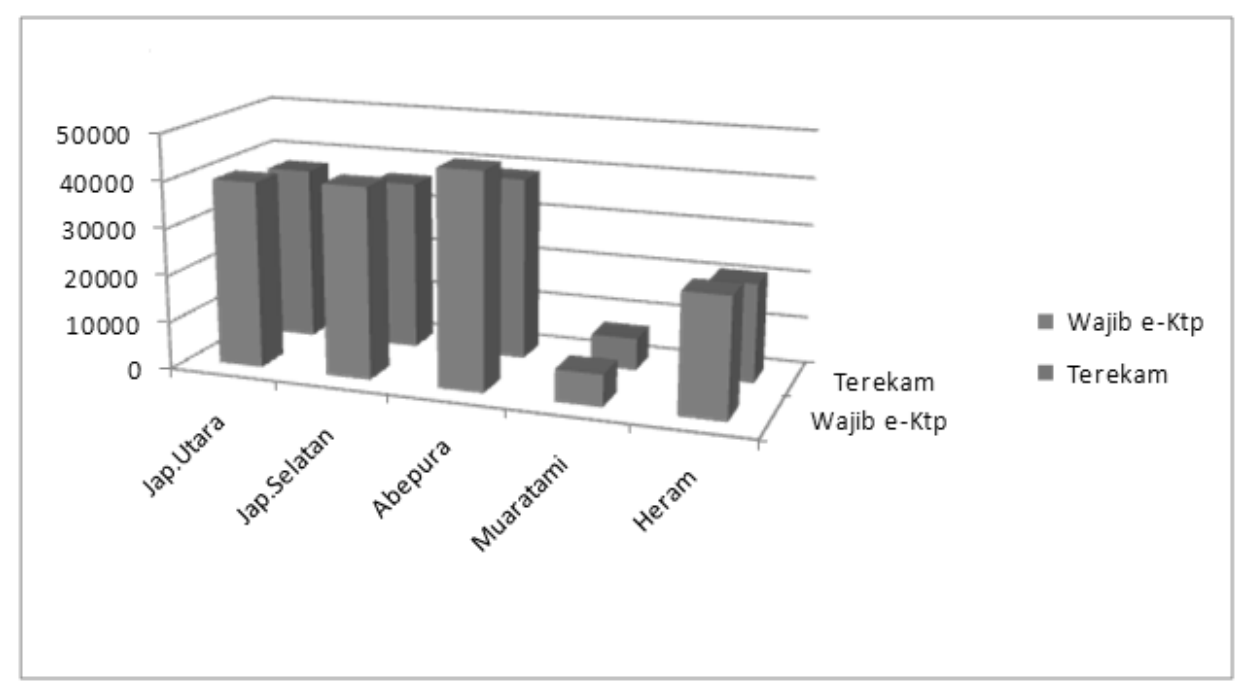

Gambar 2 : Pencapaian perekaman Per Distrik e-KTP Bulan Agustus 2012

Berdasarkan gambar 2, Distrik Muaratami merupakan satu-satunya yang hampir (95 \%) dapat menyelesaikan perekaman e-KTP. Secara berurutan berdasarkan prosentase penyelesaian maka Distrik Jayapura Utara menyelesaikan perekaman $89 \%$, Distrik Jayapura Selatan 85 \%, Distrik Abepura 82 \% dan Distrik Heram 78 \%. Distrik Jayapura Utara, Jayapura Selatan, Abepura, Heram terletak pada daerah perkotaan. Sedangkan Distrik Muaratami terletak pada daerah perdesaan.

Dari hasil pencapaian prosentase perekaman, ternyata daerah perdesaan lebih cepat mencapai prosentase penyelesaian dibandingkan daerah perkotaan. Dari hasil wawancara dengan petugas operator, dengan jumlah wajib e-KTP lebih sedikit ditemukan tinggal di asrama-asrama. Asrama dihuni mahasiswa dari berbagai daerah Kabupaten di Papua. Perkembangan perekaman e-KTP pada akhir tahun 2012, menunjukan kemajuan yang signifikan. Berdasarkan tabel 2 secara keseluruhan Kota Jayapura dapat menyelesaikan hingga 89 \%. Dalam jangka waktu 5 bulan (dari bulan Agustus 2012) menunjukan kemajuan sebesar $5 \%$. Sehingga dapat diprediksi dalam satu bulan terdapat kemajuan sebesar $1 \%$ atau sekitar 1.577 per bulan. Dari asumsi ini maka pada akhir tahun bulan November 2013 dapat diprediksi perekeman e-KTP dapat diselesaikan.

Kemajuan perekaman e-KTP apabila dilihat per Distrik secara berurutan Distrik Muaratami sudah

Tabel. 3 Perekaman e-KTP Kota Jayapura

\begin{tabular}{lllccl}
\hline No. & Distrik & $\begin{array}{l}\text { Jumlah } \\
\text { Penduduk }\end{array}$ & Wajib KTP & Sudah Terekam & Persentase \\
\hline $\mathbf{1}$ & Jayapura Utara & 65.039 & 39.664 & 37.228 & 94 \\
$\mathbf{2}$ & Jayapura Selatan & 66.937 & 40.565 & 36.078 & 89 \\
$\mathbf{3}$ & Abepura & 73.157 & 45.626 & 38.910 & 85 \\
$\mathbf{4}$ & Muara Tami & 11.137 & 6.729 & 6.794 & 101 \\
$\mathbf{5}$ & Heram & 40.435 & 25.157 & 21.005 & 83 \\
\hline & & $\mathbf{2 5 6 . 7 0 5}$ & $\mathbf{1 5 7 . 7 4 1}$ & $\mathbf{1 4 0 . 0 1 5}$ & $\mathbf{8 9}$ \\
\hline
\end{tabular}


mencapai 101 \%, Distrik Jayapura Utara $94 \%$, Distrik Jayapura Selatan 89 \%, Distrik Abepura 85 \% dan Distrik Heram 83 \%. Apabila dibandingkan dengan kemajuan prosentase bulan Agustus 2012 kenaikan prosentase tiap Distrik secara berurutan Distrik Muaratami naik 6 \%, Distrik Jayapura Utara naik $5 \%$, Distrik Jayapura Selatan naik $4 \%$, Distrik Abepura naik 3 \% dan Distrik Heram 5 \%. Kenaikan paling tinggi terjadi di Distrik Muaratami. Sedangkan distrik yang rendah kenaikan prosentasenya Distrik Abepura.

Melihat kondisi kenaikan prosentase setiap bulan sebesar $1 \%$,dapat ditingkatkan menjadi $2 \%$ per bulan. Penambahan waktu pelayanan perekaman e-KTP dari hari biasa jam kerja menjadi pelayanan 24 jam maka dapat diprediksikan meningkatkan angka pencapaian target perekaman. Memperluas jaringan pelayanan dipandang dapat meningkatkan target pencapaian perekaman. Pada pusat-pusat perbelanjaan disediakan perekaman e-KTP secara mobile. Selain pusat perbelanjaan pelayanan secara mobile dilaksanakan di pusat-pusat peribadatan.

Pelayanan perekaman e-KTP dapat ditingkatkan melalui penambahan hari kerja. Pada hari Sabtu dan Minggu dapat dimanfaatkan waktu untuk perekaman, tentunya setelah ibadah selesai. Petugas perekaman non Kristen bergantian melaksanakan perekaman. Sebaliknya pada hari Jumat petugas non muslim melaksanakan perekaman. Dengan sistem shiff kerja pelaksanaan perekaman dapat ditingkatkan. Penambahan petugas perekaman dapat memanfaatkan, distrik yang telah mencapai $100 \%$ perekaman. Selain penambahan petugas, penambahan alat perekaman turut membantu pencapaian perekaman e-KTP. Alat yang digunakan terutama berasal dari Distrik yang telah selesai melaksanakan perekaman. Progres perekaman e-KTP dapat dilihat pada gambar 3.

Pencapaian perekaman e-KTP Kota Jayapura hingga bulan Desember 2012 dapat dilihat pada gambar 3. Distrik Muaratami dapat menyelesaikan perekaman $100 \%$. Secara berurutan Distrik Jayapura Utara 94 \%, Distrik Jayapura Selatan $89 \%$, Distrik Abepura $85 \%$, Distrik Heram $83 \%$. Dibandingkan pencapaian bulan Desember 2012 maka pencapaian e- KTP sudah mengalami kenaikan prosentase.

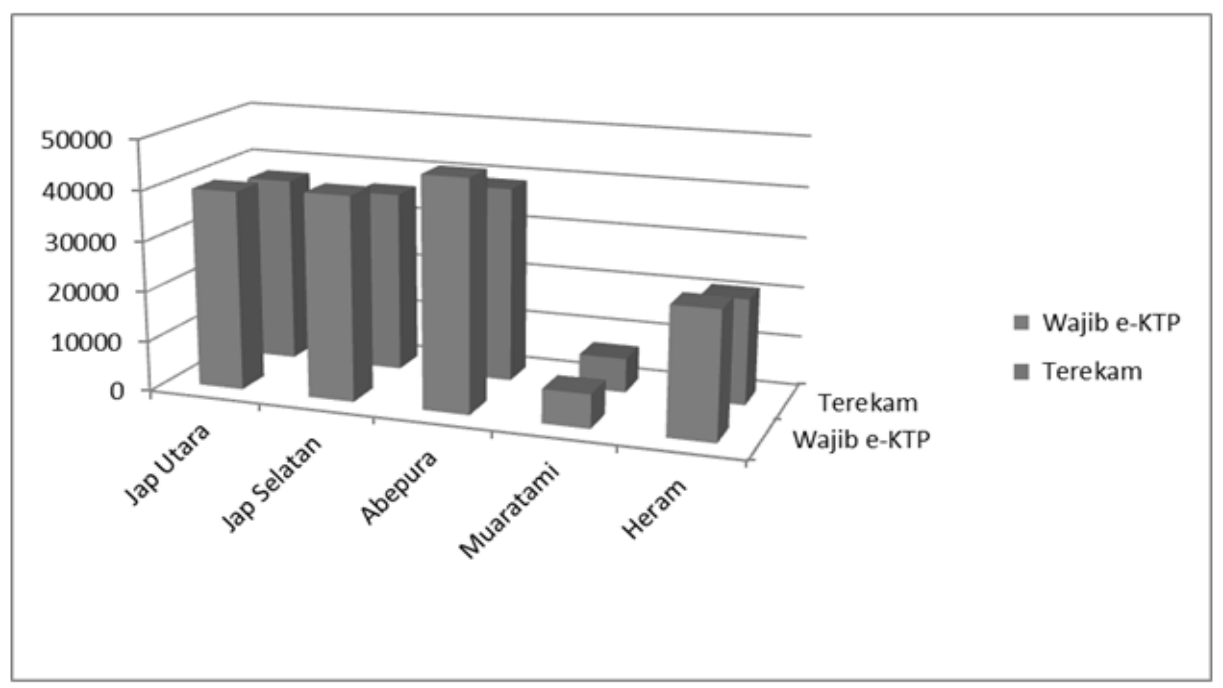

Gambar 3 : Pencapaian perekaman Per Distrik e-KTP Bulan Desember 2012. 


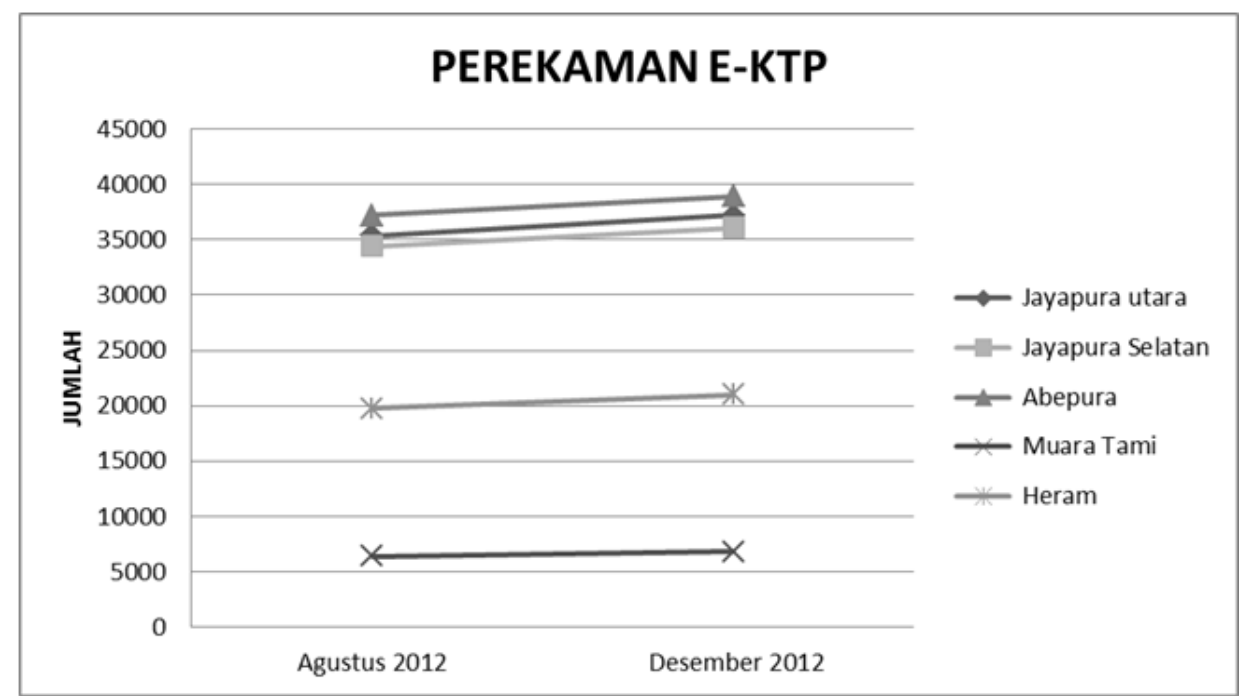

Gambar 4: Proges Perekaman e-KTP Bulan Agustus - Desember 2012.

Tabel 4: Penduduk Wajib E-KTP Belum Terekam

\begin{tabular}{llllrr}
\hline No. & Distrik & $\begin{array}{l}\text { Jumlah } \\
\text { Penduduk }\end{array}$ & $\begin{array}{l}\text { Wajib } \\
\text { KTP }\end{array}$ & $\begin{array}{l}\text { Belum } \\
\text { Terekam }\end{array}$ & Persentase \\
\hline 1 & Jayapura Utara & 65.039 & 39.664 & 4.279 & 11 \\
2 & Jayapura Selatan & 66.937 & 40.565 & 6.172 & 15 \\
3 & Abepura & 73.157 & 45.626 & 8.422 & 18 \\
4 & Muara Tami & 11.137 & 6.729 & 328 & 5 \\
5 & Heram & 40.435 & 25.157 & 5.432 & 22 \\
\hline
\end{tabular}

Sumber : Dinas Kependudukan dan Catatan Sipil Kota Jayapura Agustus 2012

Tabel 5 : Penduduk Wajib E-KTP Belum Terekam

\begin{tabular}{lllccc}
\hline No. & Distrik & Jumlah Penduduk & Wajib KTP & Belum Terekam & Persentase \\
\hline 1 & Jayapura Utara & 65.039 & 39.664 & 2.436 & 6 \\
2 & Jayapura Selatan & 66.937 & 40.565 & 4.487 & 11 \\
3 & Abepura & 73.157 & 45.626 & 6.716 & 15 \\
4 & Muara Tami & 11.137 & 6.729 & $(65)$ & -1 \\
5 & Heram & 40.435 & 25.157 & 4.152 & 17 \\
\hline
\end{tabular}

Sumber : Dinas Kependudukan dan Catatan Sipil Kota Jayapura Desember 2012

Kenaikan prosentase perekaman per Distrik maka Distrik Muaratami 5 \% ( 95 \% - 100\%) Distrik Jayapura Utara 5 \% ( 89\% - 94 \%), Jayapura Selatan $4 \%$ (85\% - 89\%), Distrik Abepura 3\% ( $82 \%-85$ $\%)$, Distrik Heram $5 \%$ (78\% - 83\%). Rata-rata perekaman e-KTP setiap Distrik kemajuan sebesar $4.4 \%$. Peningkatan perekeman e-KTP dari bulan Agustus 2012 hingga Desember 2012 menunjukan kesadaran penduduk e-KTP meningkat. Kesadaran penduduk wajib e-KTP tidak terlepas dari usahausaha Pemerintah Kota melakukan sosialisasi perekeman e-KTP. Pemberian batas akhir perekaman (dead line) ternyata sangat efektif dalam meningkatkan target perekaman. Salah satu bentuk pemberian dead line yaitu pengumuman tentang batas akhir perekaman gratis dibatasi bulan Desember 2012. Pada akhir tahun 2012 di tiap
Distrik tempat perekaman dipenuhi oleh wajib eKTP yang belum melakukan perekaman. Sosialisasi perekaman e-KTP melalui media massa lokal baik elektronik dan surat kabar memiliki peran dalam peningkatan pencapaian perekaman e-KTP. Penayangan pengumuman wajib e-KTP dalam media elektronik lokal dapat memberikan pemahaman tentang arti penting e-KTP. Di Kota Jayapura ada tiga media elektronik (stasiun TV) yaitu TOP TV, TV Papua dan TVRI Papua. Siaran televisi ini dapat diterima penduduk hingga daerah perbatasan. Media elektronik radio ikut memberikan peran dalam penyebarluasan arti penting e-KTP. Kemajuan perekaman e-KTP dari bulan Agustus 2012 hingga Desember 2012 digambarkan pada gambar 4.

Berdasarkan tabel 1, tabel 2 dan gambar 2 menunjukan kemajuan dalam pencapaian target 
perekaman e-KTP. Dari bulan Agustus 2012 hingga bulan Desember 2012 mengalami kenaikan $4.4 \%$. Distrik yang telah menyelesaikan perekaman (100\%) berdasarkan tabel 2 yaitu Distrik Muara Tami. Distrik ini merupakan distrik yang berbatasan langsung dengan negara Papua NewGuinea (PNG). Terdiri eks Transmigrasi (Koya Barat, Koya Timur, Koya Tengah) dan kampung asli (Skouwsae, Skouwyambe, Skouwmabo).

Jumlah wajib e-KTP berpengaruh terhadap penyelesaian perekaman. Distrik Muara Tami memiliki wajib e-KTP terkecil dibandingkan dengan 4 Distrik yang berada di kota. Jumlah alat perekaman di Distrik Muara Tami sebanyak 2 alat perekam . Sehingga rasio alat terhadap wajib e-KTP 1 : 3.364. Keterbatasan alat perekam pada tiap distrik berdampak masih ada penduduk wajib e-KTP belum terekam. Dari tabel 3 penduduk wajib e-KTP belum terekam Kota Jayapura hingga Agustus 2012 sebesar $16 \%$. Penduduk wajib e-KTP yang belum terekam hingga Bulan Desember 2012 dapat dilihat pada tabel 5. semakin memperkuat terlaksananya data kependudukan yang akurat. Menurunnya jumlah penduduk wajib e-KTP yang sudah terekam, menunjukan tenaga operator semakin mengusai bidang pekerjaannya. Dikuasainya alat perekaman oleh tenaga operator semakin menunjang kecepatan pelayanan bidang adminstrasi kependudukan.

\section{Hubungan Jumlah Penduduk Wajib e-KTP Dengan penyelesaian perekaman \\ Data Penduduk Wajib E-KTP}

Hubungan jumlah penduduk dengan wajib eKTP ditunjukan dalam tabel 5. Pengolahan menggunakan Software SPPS versi 19. Dari hasil analisis korelasi sederhana (r) korelasi antara jumlah penduduk dengan wajib e-KTP (r) 0,999. Hal ini menunjukan bahwa terjadi hubungan yang sangat kuat antara jumlah penduduk dengan wajib e-KTP. Sedangkan arah hubungan adalah positif karena nilai r positif.

Tabel 6 : Hubungan Jumlah Penduduk dengan Wajib

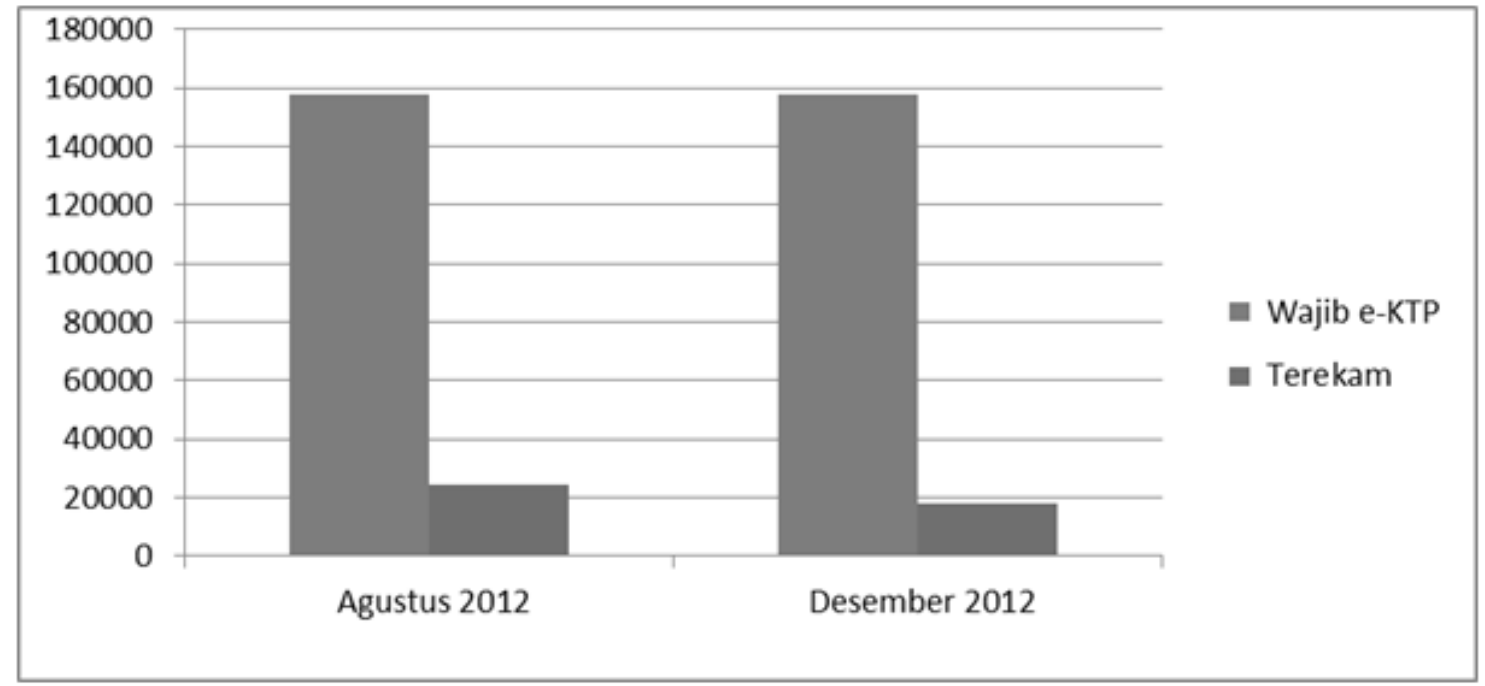

Gambar 5 : Penduduk Wajib E-KTP Belum Terekam.

Berdasarkan gambar 5 jumlah penduduk wajib e-KTP yang belum terekan semakin berkurang. Bulan Agustus 2012 jumlah penduduk belum terekam 24.633 atau $16 \%$. Kemajuan perekaman ditunjukan pada akhir tahun 2012, yaitu jumlah penduduk belum terekam tersisa 17.726 (11 \%). Penurunan jumlah penduduk wajib e-KTP yang belum terekam, menunjukan kemajuan dalam peningkatan pencapaian target perekaman wajib eKTP. Penurunan angka mengindikasikan kesadaran warga wajib e-KTP semakin baik. Dari sisi pelayanan menunjukan semakin meningkatnya pelayanan.

Peningkatan pelayanan di bidang administrasi kependudukan melalui pelayanan e-KTP akan dapat mewujudkan tertib adminstrasi kependudukan. Data base kependudukan melalui perekaman wajib e-KTP

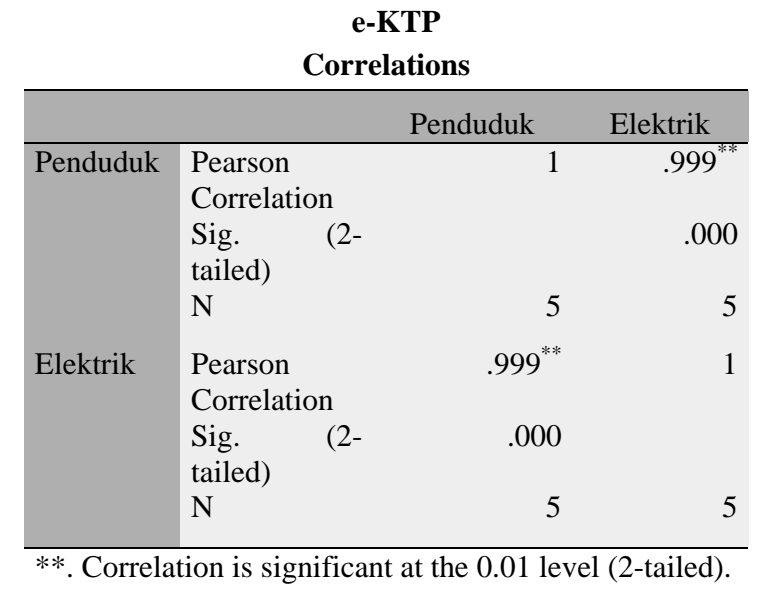

e-KTP

Correlations

\begin{tabular}{|c|c|c|c|}
\hline & & Penduduk & Elektrik \\
\hline \multirow[t]{3}{*}{ Penduduk } & Pearson & 1 & $.999^{* *}$ \\
\hline & $\begin{array}{l}\text { Sig. } \\
\text { tailed) }\end{array}$ & & .000 \\
\hline & $\mathrm{N}$ & 5 & 5 \\
\hline \multirow[t]{3}{*}{ Elektrik } & $\begin{array}{l}\text { Pearson } \\
\text { Correlation }\end{array}$ & $.999^{* *}$ & 1 \\
\hline & $\begin{array}{l}\text { Sig. } \\
\text { tailed) }\end{array}$ & .000 & \\
\hline & $\mathrm{N}$ & 5 & 5 \\
\hline
\end{tabular}


Sedangkan untuk melihat hubungan jumlah penduduk wajib e-KTP dengan penyelesaian perekaman ditunjukan pada tabel 6. Dari tabel 6 kolom "penduduk" menunjukan jumlah penduduk wajib e-KTP. Sedangkan kolom "perekaman “ adalah jumlah penduduk yang sudah melaksanakan perekaman.

Tabel 7 : Hubungan Jumlah wajib e-KTP dengan Penyelesaian Perekaman Correlations

\begin{tabular}{llrr}
\hline & & Penduduk & Perekaman \\
\hline Penduduk & Pearson & 1 & $.923^{*}$ \\
& Correlation & & \\
& Sig. (2-tailed) & & .025 \\
& N & 5 & 5 \\
Perekaman & Pearson & $.923^{*}$ & 1 \\
& Correlation & & \\
& Sig. (2-tailed) & .025 & \\
& N & 5 & 5 \\
\hline *. Correlation is significant at the 0.05 level (2-tailed).
\end{tabular}

Dari hasil analisis (r) korelasi antara jumlah penduduk wajib e-KTP dengan penyelesaian perekaman e-KTP (r) 0,923. Hal ini menunjukan bahwa terjadi hubungan yang sangat kuat antara jumlah penduduk dengan penyelesaian perekaman e-KTP. Arah hubungan adalah positif karena nilai $r$ positif.

\section{Hambatan Dalam Perekaman e-KTP}

Perekaman e-KTP di Kota Jayapura dalam pelaksanaannya ditemukan hambatan. Berdasarkan wawancara dengan petugas operator maka hambatan dapat dikelompokan dalam dua sisi alat perekaman dan penduduk.

1. Kerusakan Alat perekam

Alat perekam e-KTP didatangkan dari pusat (Kemendagri). Terdiri satu unit Komputer (Keyboard, CPU, Monitor, Mouse), alat scan sidik jari, alat perekam iris mata, camera, server dan kain baground (merah, biru). Kerusakan alat ditemukan pada saat perekaman. Kerusakan alat perekam belum bisa diperbaiki oleh petugas servis lokal. Perbaikan menunggu hasil konsultasi dengan pusat, baru dapat diperbaiki. Konsultasi dengan pusat menyita waktu, perekaman tersita waktu menunggu perbaikan alat.

2. Alat Perekam Terbatas

Setiap distrik di Kota Jayapura memperoleh alokasi 2 alat perekam. Terbatasnya alat perekam menimbulkan antrian panjang penduduk wajib e-KTP. Alat perekam tambahan berupa alat mobile yang dapat bergerak dari satu distrik ke distrik laiinya dioperasikan Dinas Kependudukan dan Catatan Sipil. Jumlah alat perekam standar di Kota Jayapura sebanyak 11 alat perekam. Ada tambahan alat perekam sebanyak 9 unit. Sehingga mulai tanggal 16
Desember 2011 total alat berjumlah 20 unit. Tambahan alat perekam khusus Distrik yang memiliki penduduk wajib e-KTP yang jumlahnya banyak.

3. Gangguan Server

Kondisi morfologis Kota Jayapura bervariasi. Daerah Muaratami sebagian besar berupa dataran. Sedangkan distrik lainnya (Jayapura Utara, Jayapura Selatan, Heram, Abepura) bervariasi dari dataran hingga gunung-gunung. Perekaman e-KTP menggunakan server dan langsung diterima di Pusat. Kondisi morfologis memiliki dampak terhadap pengiriman data. Ganguan server oleh kondisi alam berpengaruh pada kelancaran pengiriman data server ke pusat. Gangguan server berakibat perekaman eKTP terhenti. Penduduk wajib e-KTP harus menunggu hingga server normal kembali.

4. Listrik Padam

Pasokan listrik untuk perkantoran di Kota Jayapura disuplay oleh PLN. Semakin banyaknya konsumen tidak dibarengi peningkatan daya listrik berakibat pemadaman secara bergiliran. Pemadaman bergiliran mempengaruhi pada perekaman e-KTP. Distrik disediakan genset, tetapi pergantian dari listrik PLN ke genset membutuhkan waktu. Akibatnya penduduk wajib e-KTP bersabar untuk menunggu, hingga listrik berjalan normal.

5. Pencetakan e-KTP terlambat

Seluruh pencetakan e-KTP dilaksanakan di Jakarta. Penduduk wajib e-KTP yang sudah melaksanakan perekaman, menunggu rata-rata 2-3 bulan. Dari data wajib e-KTP yang telah melakukan perekaman sebanyak 140.015, tercetak 123.758. atau 88,3 \%

6. Mata Katarak

Penduduk wajib e-KTP pengidap katarak, mengurangi kecepatan perekaman iris mata. Dari hasil wawancara dengan operator, satu orang dapat memakan waktu satu jam. Akibatnya antrian semakin panjang.

7. Sidik Jari Tidak Jelas

Kesulitan yang ditemui oleh operator ada penduduk wajib e-KTP sidik jari tidak kentara (jelas). Sehingga berpengaruh pada kecepatan perekaman sidik jari. Pengambilan sidik jari berulang-ulang berakibat antrian perekaman eKTP.

\section{Upaya Mengatasi Kendala Perekaman e-KTP}

Mendukung kebijakan Kementerian Dalam Negeri, Pemerintah Kota Jayapura melalui Dinas Kependudukan dan Catatan Sipil berupaya mencapai target perekeman. Upaya yang telah dilakukan untuk mencapai dan mempercepat target perekaman ditemukan sebagai berikut :

1. Penyisiran e-KTP tingakt RT/RW

Penyisiran dilakukan di tiap-tiap RT/RW dengan tujuan menginventarisir penduduk wajib e-KTP 
yang belum melakukan perekaman. Dalam penyisiran ini dilakukan dengan melibatkan RT/RW setempat. Daerah-daerah yang dianggap masih rendah capaiannya dilakukan penyisiran.

2. Pengumuman Media Elektronik dan Surat Kabar Himbauan arti penting e-KTP disebarluaskan melalui media Televisi maupun Radio. Siaran radio sangat membantu dalam menyebarluaskan himbauan Pemerintah Kota. Pada pagi hari melalui siaran RRI selalui ada himbauan batas waktu perekaman. Media televisi di Papua TV, TOP TV digunakan Pemerintah Kota Jayapura dalam menyebarluaskan himbauan dan batas akhir perekaman. Surat kabar yang digunakan berupa surat kabar lokal : Cenderawasih Pos, Bisnis Papua, Bintang Papua. Surat kabar ini memuat himbauan batas akhir perekaman eKTP.

3. Pelayanan Mobile

Dinas Kependudukan dan catatan sipil memimilki satu unit mobil, yang didesain sebagai mobil pelayanan keliling. Pelayanan mobile ini terutama membantu distrik, yang masih mengalami kekurangan alat perekam. himbauan perekaman dipasang setiap kelurahan/kampung. Himbauan perekaman dapat pula dipasang secara mobile. Untuk memperluas jangkauan himbauan ada terobosan dengan menggunakan Kendaraan dinas milik pemerintah Kota Jayapura. Kendaraan dapat dipasang stiker pada kaca bagian belakang yang berisi himbauan batas akhir perekaman e-KTP. Kendaraan dinas ini bergerak hampir diseluruh wilayah pemerintahan Kota Jayapura.

6. Kunjungan ke Asrama-asrama

Langkah ini diambil untuk lebih mengenalkan eKTP untuk penghuni asrama. Pemerintah Kabupaten hampir memiliki asrama dari daerah masing-masing untuk menampung mahasiswa yang menuntut ilmu di Sekolah/Perguruan Tinggi di Jayapura.

\section{Rasio alat Perekaman Dengan Jumlah Penduduk Wajib e-KTP}

Jumlah dan Peralatan alat perekaman di Kota Jayapura keseluruhan berjumlah 20 unit. Untuk melihat rasio alat perekeman di Kota Jayapura ditunjukan pada tabel 8 berikut :

Tabel 5 : Peralatan perekaman E-KTP

\begin{tabular}{lllcccc}
\hline $\begin{array}{l}\text { No } \\
\cdot\end{array}$ & Distrik & $\begin{array}{l}\text { Jumlah } \\
\text { Penduduk }\end{array}$ & $\begin{array}{l}\text { Wajib } \\
\text { KTP }\end{array}$ & $\begin{array}{l}\text { Pemberian } \\
\text { Alat } \\
\text { Standar }\end{array}$ & Tambahan & Jumlah \\
\hline 1 & Jayapura Utara & 65.039 & 39.664 & 2 & 3 & 5 \\
2 & Jayapura Selatan & 66.937 & 40.565 & 2 & 2 & 4 \\
3 & Abepura & 73.157 & 45.626 & 2 & 3 & 5 \\
4 & Muara Tami & 11.137 & 6.729 & 2 & 0 & 2 \\
5 & Heram & 40.435 & 25.157 & 2 & 1 & 3 \\
6 & Dispenduk(Mobile) & & & 1 & 0 & 1 \\
\hline & & $\mathbf{2 5 6 . 7 0 5}$ & $\mathbf{1 5 7 . 7 4 1}$ & $\mathbf{9}$ & $\mathbf{1 1}$ & $\mathbf{2 0}$ \\
\hline
\end{tabular}

Sumber : Dinas Kependudukan dan Catatan Sipil Kota Jayapura Desember 2012

Selain distrik pada waktu yang telah ditentukan melakukan perekeman pada tempat yang telah ditetapkan. Posyandu menjadi event yang dapat dimanfaatkan untuk melakukan perekaman eKTP.

4. Peminjaman Alat Perekaman

Salah satu cara yang ditempuh untuk mempercepat perekaman e-KTP meminjam alat perekam. Distrik yang sudah mencapai target, meminjamkan alat untuk digunakan di Distrik laiinya yang masih rendah pencapaian perekaman. Pemerintah Provinsi Papua melalui Dinas Kependudukan dan Transmigrasi memberikan pinjaman alat perekaman e-KTP. Alat perekam di Kota Jayapura seluruhnya berjumlah 20 unit.

5. Pemasangan Himbauan

Spanduk dan baner dipasang di tempat-tempat strategis. Baner dipasang dipinggir jalan berisi himbauan untuk batas akhir perekaman gratis. Tahun 2013 perekaman terakhir berakhir 31 Mei 2013. Selain di tempat strategis pemasangan

\section{SIMPULAN}

Berdasarkan hasil penelitian dan pembahasan maka dapat disimpulkan sebagai berikut : Pertama, pelaksanaan kebijakan e-KTP di Kota Jayapura telah dilaksanakan dan mencapai kemajuan yang signifikan . Perkembangan perekaman e-KTP pada akhir tahun 2012, menunjukan hingga 89 \%. Dalam jangka waktu 5 bulan (dari bulan Agustus Desember 2012) mengalami perkembangan sebesar $5 \%$. Dari angka kemajuan pencapaian perekaman dapat diproyeksikan pada akhir tahun 2013 perekaman akan dapat diselesaikan.

Kedua, terdapat hubungan antara jumlah penduduk dengan wajib e-KTP dalam arti semakin besar jumlah penduduk di Kota Jayapura akan semakin besar pula penduduk wajib e-KTP. Hubungan antara jumlah wajib e-KTP dengan penyelesian perekaman e-KTP terdapat hubungan. Dalam pelaksanaan perekaman e-KTP ditemukan sejumlah hambatan. Hambatan yang muncul telah diatasi dengan berbagai upaya yang telah 
dilaksanakan oleh Pemerintah Kota Jayapura. Dengan berbagai upaya yang ada, maka dapat mempercepat penyelesaian perekaman dari akhir tahun ke pertengahan tahun 2013. Rasio alat perekaman e-KTP menunjukan 1alat perekaman : 7.887 penduduk wajib e-KTP.

Adapun saran yang dapat disampaikan antara lain: Pertama, Pemerintah Kota Jayapura melalui Dinas Kependudukan dan Catatan Sipil selalu meningkatkan peringatan/himbauan batas waktu perekaman kepada penduduk wajib e-KTP. Himbauan dilaksanakan pula di tempat-tempat ibadah, asrama. Mengerahkan pengurus RT untuk menjaring warga wajib e-KTP yang belum melaksanakan perekaman.

Kedua, Pemerintah Kota Jayapura melalui Dinas Kependudukan dan Catatan Sipil memantau pelaksanaan e-KTP di Distrik, terutama penduduk wajib e-KTP yang jumlahnya tinggi. Untuk menjaring penduduk wajib e-KTP yang belum melakukan perekeman perlu memberlakukan operasi justisia e-KTP Plus. Penduduk wajib e-KTP yang terjaring diberikan kesempatan melaksnakan perekaman. Perekaman semakin dipermudah dengan menyediakan tempat perekaman di pusat-pusat keramaian (mall).

Ketiga, distrik yang telah selesai melaksanakan perekaman perlu diberikan reward agar dapat memacu distrik laiinya yang belum selesai melaksnakan perekaman e-KTP.

\section{DAFTAR PUSTAKA}

Hadi Setia Tunggal (2007) Undang-Undang Administrasi Kependudukan (UU Nomor 23 Tahun 2006) Harvarindo

Sarwono Jonathan (2011) Mixed Metods, Jakarta, Elex Media Komputindo

Sugiyono (2007) Metodologi Penelitian, Bandung, Alfabeta

--(2012) Laporan Kemajuan Perekaman e-KTP, Jayapura, DISDUKCAPIL Kota Jayapura

Wahana Andi dan Penerbit Andi (2012) SPSS 20 untuk Pengolahan Data, Yogyakarta, Penerbit Andi. 